\title{
Lmo0036, an ornithine and putrescine carbamoyltransferase in Listeria monocytogenes, participates in arginine deiminase and agmatine deiminase pathways and mediates acid tolerance
}

Correspondence
Weihuan Fang
whfang@zju.edu.cn

Received 10 March 2011

Revised 21 June 2011

Accepted 9 August 2011
Jianshun Chen, ${ }^{1}$ Changyong Cheng, ${ }^{1}$ Ye Xia, ${ }^{1}$ Hanxin Zhao, ${ }^{1}$ Chun Fang, ${ }^{1}$
Ying Shan, ${ }^{1}$ Beibei $\mathrm{Wu}^{2}$ and Weihuan Fang ${ }^{1}$

\author{
${ }^{1}$ Zhejiang University Institute of Preventive Veterinary Medicine and Zhejiang Provincial Key \\ Laboratory of Preventive Veterinary Medicine, 388 Yuhangtang Road, Hangzhou, Zhejiang \\ 310058, PR China \\ ${ }^{2}$ Zhejiang Provincial Center for Disease Control and Prevention, 630 Xincheng Road, Hangzhou, \\ Zhejiang 310051, PR China
}

\begin{abstract}
Listeria monocytogenes is a foodborne pathogen causing listeriosis. Acid is one of the stresses that foodborne pathogens encounter most frequently. The ability to survive and proliferate in acidic environments is a prerequisite for infection. However, there is limited knowledge about the molecular basis of adaptation of $L$. monocytogenes to acid. Arginine deiminase (ADI) and agmatine deiminase $(\mathrm{AgDl})$ systems are implicated in bacterial tolerance to acidic environments. Homologues of ADI and AgDI systems have been found in L. monocytogenes lineages I and II strains. Sequence analysis indicated that Imo0036 encodes a putative carbamoyltransferase containing conserved motifs and residues important for substrate binding. Lmo0036 acted as an ornithine carbamoyltransferase and putrescine carbamoyltransferase, representing the first example, to our knowledge, that catalyses reversible ornithine and putrescine carbamoyltransfer reactions. Catabolic ornithine and putrescine carbamoyltransfer reactions constitute the second step of ADI and AgDI pathways. However, the equilibrium of in vitro carbamoyltransfer reactions was overwhelmingly towards the anabolic direction, suggesting that catabolic carbamoyltransferase was probably the limiting step of the pathways. Imo0036 was induced at the transcriptional level when L. monocytogenes was subjected to low-pH stress. Its expression product in Escherichia coli exhibited higher catabolic carbamoyltransfer activities under acidic conditions. Consistently, absence of this enzyme impaired the growth of Listeria under mild acidic conditions $(\mathrm{pH} \mathrm{4.8)}$ and reduced its survival in synthetic human gastric fluid ( $\mathrm{pH} 2.5$ ), and corresponded to a loss in ammonia production, indicating that $\mathrm{Lmo0036}$ was responsible for acid tolerance at both sublethal and lethal $\mathrm{pH}$ levels. Furthermore, Lmo0036 played a possible role in Listeria virulence.
\end{abstract}

\section{INTRODUCTION}

Listeria monocytogenes is the causative agent of listeriosis, a severe disease that has an extremely high mortality rate (Freitag et al., 2009; Liu, 2006). Foodborne transmission is the most common means of contracting both epidemic and sporadic listeriosis, with $99 \%$ of human cases caused by consumption of contaminated food products (Chen et al., 2009a; Swaminathan \& Gerner-Smidt, 2007). However, not all $L$. monocytogenes strains contribute equally to human

Abbreviations: $\mathrm{ADI}$, arginine deiminase; $\mathrm{AgDI}$, agmatine deiminase; aOTC, anabolic OTC; aPTC, anabolic PTC; CK, carbamate kinase; cOTC, catabolic OTC; cPTC, catabolic PTC; OTC, ornithine carbamoyltransferase; PTC, putrescine carbamoyltransferase; qRT-PCR, quantitative RT-PCR; UPLC, ultraperformance liquid chromatography. illness (Orsi et al., 2011). Among the four evolutionary lineages, only lineages I and II are commonly isolated from contaminated foods and human listeriosis patients (Orsi et al., 2011; Ward et al., 2008). The virulence potential of L. monocytogenes is linked to its ability to survive adverse environmental conditions encountered both in natural environments and subsequently within the host (Ryan et al., 2009; Sleator et al., 2009). An elevated level of acid is often added to foods to inhibit bacterial growth (Byelashov et al., 2010). After ingestion via contaminated foods, L. monocytogenes encounters the acidic conditions of the gastric barrier, followed by exposure to fatty acid in the intestine (Sleator et al., 2009). Survival in the host gastrointestinal tract is the key stage for initiating listerial infection. Following cellular uptake, L. monocytogenes enters the acidic 
vacuole of the macrophage phagosome (de Chastellier \& Berche, 1994). Undoubtedly, acid represents one of the most frequently encountered stresses for foodborne pathogens like L. monocytogenes. It should possess mechanisms for $\mathrm{pH}$ homeostasis that allow its survival and proliferation under acidic conditions.

The arginine deiminase (ADI) system has been characterized in several Gram-positive and Gram-negative bacteria and implicated in bacterial tolerance to acidic environments (Degnan et al., 2000; Gruening et al., 2006; Marquis et al., 1987; Vrancken et al., 2009a). Three enzymes constitute the deiminase pathway that catalyses the conversion of arginine into ornithine, $\mathrm{NH}_{3}, \mathrm{CO}_{2}$ and ATP, namely ADI, catabolic ornithine carbamoyltransferase (cOTC) and carbamate kinase (CK), which are encoded by $\operatorname{arc} A, \operatorname{arcB}$ and $\operatorname{arcC}$ respectively (Fig. 1a, c, e). Ornithine is transported out of the cell in exchange for a molecule of arginine by a transporter encoded by $\operatorname{arcD}$. The byproduct $\mathrm{NH}_{3}$ can combine with intracellular cytoplasmic protons to yield ammonium ions $\left(\mathrm{NH}_{4}^{+}\right)$, thereby increasing intracellular $\mathrm{pH}$ and protecting cells from acidic damage (Cunin et al., 1986). In addition, ATP can be used to extrude protons via the $\mathrm{F}_{0} \mathrm{~F}_{1}$-ATPases, which play a role in $\mathrm{pH}$ homeostasis (Cotter et al., 2000). A similar pathway has been described for agmatine, the decarboxylation product of arginine which yields putrescine and ammonia upon catalysation (Griswold et al., 2004; Llácer et al., 2007; Lucas et al., 2007). Less is known about the agmatine deiminase (AgDI) pathway, which involves the AgDI enzyme itself, catabolic putrescine carbamoyltransferase (cPTC) and CK (Fig. 1b, d, e) (Griswold et al., 2004; Llácer et al., 2007; Lucas et al., 2007).

Homologues of ADI and AgDI systems have been found in the genomes of $L$. monocytogenes strains. To our knowledge, L. monocytogenes represents the first example harbouring both ADI and AgDI systems at the same genetic locus (Chen, 2010), e.g. the lmo0036-lmo0043 region in the strain EGD-e (Glaser et al., 2001). Interestingly, Joseph et al. (2006) detected the upregulation of $1 m 00036$ during infection of Caco-2 cells. Ryan et al. (2009) speculated that Lmo0036 was cOTC, subsequent to the functional characterization of ADI (encoded by lmo0043). However, Naumoff et al. (2004) suggested that Lmo0036 was a putrescine carbamoyltransferase (PTC) orthologue based on the systematic evolutionary tree of carbamoyltransferases from a variety of bacterial species including $L$. monocytogenes.

Functionally catabolic carbamoyltransferases have been found in a number of bacteria, e.g. Enterococcus faecalis (Llácer et al., 2007), Pseudomonas aeruginosa (Sainz et al., 1998), Streptococcus mutans (Casiano-Colón \& Marquis, 1988) and Lactobacillus hilgardii (Arena et al., 2002), and

(a)

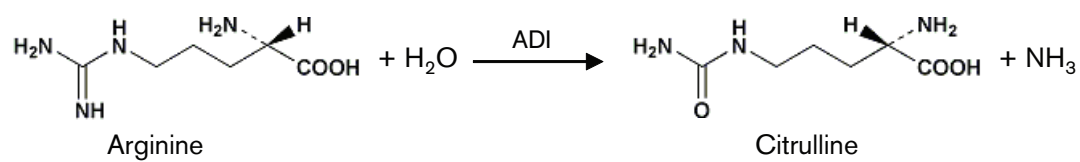

(b)

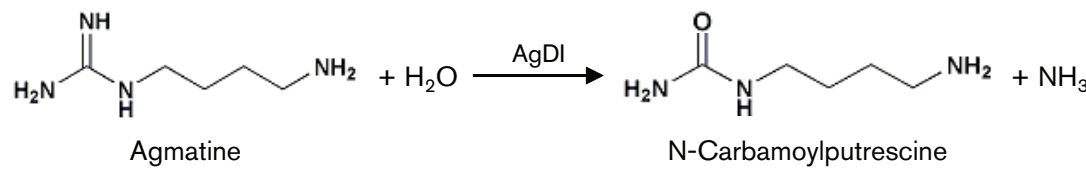

(c)

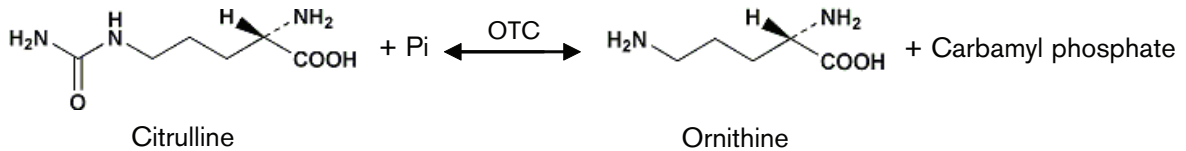

(d)

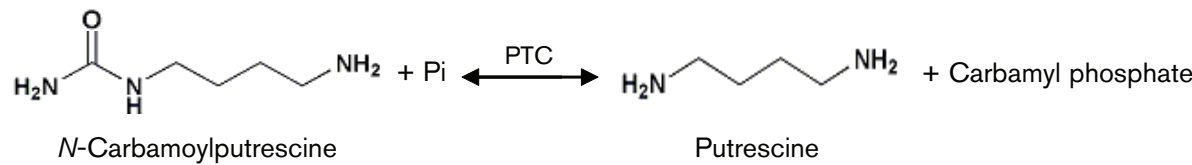

(e)

Carbamyl phosphate $+\mathrm{ADP} \stackrel{\mathrm{CK}}{\longrightarrow} \quad \mathrm{ATP}+\mathrm{NH}_{3}+\mathrm{CO}_{2}$

Fig. 1. The $\mathrm{ADI}$ and $\mathrm{AgDI}$ pathways. OTC, ornithine carbamoyltransferase; PTC, putrescine carbamoyltransferase; CK, carbamate kinase. 
these are of critical importance for ADI and AgDI pathways involved in $\mathrm{pH}$ homeostasis and microbial ecology. While cOTC mediates the decarbamoylation of citrulline (the deimination product of arginine) yielding carbamoylphosphate and ornithine (Fig. 1c) (Legrain \& Stalon, 1976), cPTC catalyses the decarbamoylation reaction of carbamoylputrescine (the deimination product of agmatine) producing carbamoylphosphate and putrescine (Fig. 1d) (Wargnies et al., 1979). However, little is known about the function of Lmo0036, the putative carbamoyltransferase in L. monocytogenes. Therefore, this study attempted to examine the functional activity of Lmo0036 and its roles in acid stress response and virulence potential of $L$. monocytogenes.

\section{METHODS}

Bacterial strains and growth conditions. L. monocytogenes reference strain $10403 \mathrm{~S}$ was used as the wild-type strain and another 40 L. monocytogenes strains covering four lineages have been described in our previous studies (Chen et al., 2009b, 2010a). L. monocytogenes and Escherichia coli strains were propagated at $37{ }^{\circ} \mathrm{C}$ in brain heart infusion (BHI) broth (Oxoid) and Luria-Bertani (LB) medium, respectively. Stock solutions of ampicillin $\left(100 \mathrm{mg} \mathrm{ml}^{-1}\right)$, kanamycin $\left(50 \mathrm{mg} \mathrm{ml}^{-1}\right)$ and chloramphenicol $\left(50 \mathrm{mg} \mathrm{ml}^{-1}\right)$ were added to media, where appropriate, at the required levels.

Bioinformatic analysis. Amino acid sequences of Lmo0036 in $L$. monocytogenes and its homologues in other bacterial species were obtained from the NCBI database (http://www.ncbi.nlm.nih.gov/). These sequences were aligned by CLUSTAL_X software (version 1.8). A phylogenetic tree was constructed using the Neighbor-Joining method of the Molecular Evolutionary Genetics Analysis software (MEGA version 4.0). The robustness of the branching pattern was tested by bootstrap analyses through 1000 replications. Putative enzyme active sites were predicted via the ExPASy Proteomics Server (http://www.expasy.ch/).

DNA manipulations. Genomic DNA was prepared using a protocol reported previously (Chen et al., 2009c). Oligonucleotide primers were synthesized by Invitrogen Biotechnology (Table 1). PCR was conducted using a PT200 thermal cycler (MJ Research), with the duration of extension depending on the expected length of the amplicon $\left(1 \mathrm{~min} \mathrm{~kb}^{-1}\right.$, at $\left.72{ }^{\circ} \mathrm{C}\right)$. PCR fragments were purified using the AxyPrep DNA Gel Extraction kit (Axygen) and digested with defined restriction enzymes (TaKaRa) to facilitate insertion into vectors. Positive clones were then sequenced by using the dideoxy method on an ABI-PRISM 377 DNA sequencer.

Construction of Imo0036 knockout mutant. A homologous recombination strategy was used for in-frame deletion of the whole length of lmo0036 (1026 bp) in L. monocytogenes $10403 \mathrm{~S}$ according to a protocol described previously (Chen et al., 2009d). Primer pairs 36$\mathrm{a} / 36-\mathrm{b}$ and $36-\mathrm{c} / 36-\mathrm{d}$ were used to generate fragments of 588 and $640 \mathrm{bp}$ from flanking regions of $l m o 0036$ (Table 1). The two products were gel purified for splicing by overlap-extension PCR using external primer pair 36-a/36-d. The final 1216 bp product containing HindIII and EcoRI sites was digested and ligated to pUC18. After sequencing confirmation, the inserted fragment was subcloned into the thermosensitive shuttle vector pKSV7, which was then electro-transformed into the competent L. monocytogenes cells. Electrotransformants were grown at a non-permissive temperature $\left(41{ }^{\circ} \mathrm{C}\right)$ in $\mathrm{BHI}$ containing chloramphenicol $\left(10 \mu \mathrm{g} \mathrm{ml}^{-1}\right)$ to screen for chromosomal integration and the cointegrates were passaged successively in BHI without antibiotic at a permissive temperature $\left(30^{\circ} \mathrm{C}\right)$ to facilitate isolation of derivatives in which integrated plasmids had resolved by a second recombination event. The recombinants were identified as chloramphenicol-sensitive colonies and confirmed by PCR with primers 36-e/36-f (external to 36-a/36-d). The resultant knockout mutant was designated $\Delta \mathrm{lmo} 0036$.

Complementation of the Imo0036 deletion. The 1 mo0036 coding sequence (including the ribosome-binding site) was amplified from 10403 genomic DNA by PCR using primers 36-pER-F and 36-pER-R (Table 1). The 1278 bp product containing SacI and BamHI sites was digested and ligated to pUC18. After sequencing confirmation, the inserted fragment was subcloned into the vector pERL3. The resulting vector was electroporated into $\Delta \mathrm{lmo} 0036$ and a transformant was selected on BHI erythromycin plates. The resultant complemented mutant was designated $\Delta \mathrm{lmo} 0036+\operatorname{lmo} 0036$.

Table 1. Oligonucleotide primers used in this study

Restriction sites incorporated into primer sequences are underlined.

\begin{tabular}{|c|c|c|c|}
\hline $\begin{array}{l}\text { Primer } \\
\text { name }\end{array}$ & Primer $\left(5^{\prime}-3^{\prime}\right)$ & Amplicon size (bp) & Description \\
\hline 36-pET-F & CGAGGATCCATGAACAAAAAAAGAGATTT & 1026 & Used for cloning of $\operatorname{lmo} 0036$ \\
\hline 36-pET-R & TATAAGCTTTTATAAGCCAGCGCCATTTC & & \\
\hline 36-RT-F & CGGTCGCAAAATGAAAGAATC & 145 & Used for $\mathrm{qRT}-\mathrm{PCR}$ \\
\hline 36-RT-R & CGCATGACCACCAAGCTGT & & \\
\hline gyrB-RT-F & AGACGCTATTGATGCCGATGA & 91 & \\
\hline gyrB-RT-R & GTATTGCGCGTTGTCTTCGA & & \\
\hline $36-\mathrm{a}$ & ATAAGCTTTTTAGAAGCGTTTATGCAT & 588 & Used for construction of $1 m o 0036$ null mutant \\
\hline $36-\mathrm{b}$ & CCTTATTTTGGTATCTTCTATCACCTCA & & \\
\hline $36-c$ & GATACCAAAATAAGGAGGAGAAGAGAGC & 640 & \\
\hline $36-d$ & TAGAATTCTCAAAAGTTGGAAGTAATGC & & \\
\hline $36-c$ & GGATATGGTCCTACTGTTGGA & 2392 & Used to screen the positive clones of $\operatorname{lmo} 0036$ null mutant \\
\hline $36-d$ & GCGTTGTTACCACTTCAAAAC & & \\
\hline 36-pER-F & ATTGAGCTCGAGAGGCTAATAGACTGGAAA & 1278 & Used for complementation of the lmo0036 deletion \\
\hline 36-pER-R & TATGGATCCTTATAAGCCAGCGCCATT & & \\
\hline
\end{tabular}


Expression and purification of Lmo0036. The Imo0036 gene was amplified by PCR using primers 36-pET-F and 36-pET-R (Table 1) and inserted into pET30a downstream of an in-frame sequence encoding an $\mathrm{N}$-terminal histidine tag. The recombinant plasmid was transferred into E. coli Rosetta. E. coli cells carrying pET30a-lmo0036 were grown until the cultures reached $\mathrm{OD}_{600}$ 0.6; IPTG was added to a final concentration of $0.4 \mathrm{mM}$ and the cultures were allowed to grow for an additional $3 \mathrm{~h}$. The cells were collected, resuspended in PBS $(50 \mathrm{mM}$, $\mathrm{pH}$ 7.2) and disrupted in a sonicator with 99 cycles of sonication at $300 \mathrm{~W}$ for $4 \mathrm{~s}$ with intermittent cooling on ice for $4 \mathrm{~s}$, followed by centrifugation at 12000 r.p.m. The supernatant was loaded onto a HiTrap chelating column saturated with a solution of $\mathrm{NiCl}_{2}$. After washing the column with PBS containing $500 \mathrm{mM} \mathrm{NaCl}$ and $20 \mathrm{mM}$ imidazole, bound protein was eluted with a linear gradient of 20$500 \mathrm{mM}$ imidazole prepared in the same buffer. Protein concentration was determined on a Nanodrop ND-1000 spectrophotometer (Nanodrop Technologies). The preparations were analysed by SDSPAGE, followed by Coomassie brilliant blue staining. E. coli cells carrying empty vector pET30a were employed as negative controls.

Site-directed mutagenesis. To identify the predicted active sites of Lmo0036, mutations (Table 2) were engineered into pET30a-lmo0036 using the QuikChange Site-Directed Mutagenesis kit (Stratagene). All segments that were manipulated were sequenced to confirm the presence of the desired mutation and to exclude adventitious mutations. Expression and purification of variant Lmo0036 proteins were performed at optimal $\mathrm{pH}$ conditions as described above.

Determination of in vitro catabolic ornithine and putrescine carbamoyltransfer activities. The reaction was conducted at $37{ }^{\circ} \mathrm{C}$ and initiated by adding $0.5 \mu \mathrm{M}$ purified Lmo0036 into solution A ( $8 \mathrm{mM}$ citruline or $\mathrm{N}$-carbamoylputrescine, $240 \mathrm{mM}$ arsenate and $8 \mathrm{mM}$ uridine monophosphate, $\mathrm{pH} 2.0-9.0$ ) and terminated at the indicated time points by adding $50 \mu 150 \%$ TCA. The enzyme activity was measured based on depletion of the substrates, citrulline or $\mathrm{N}$ carbamoylputrescine, using a modified version of the method of Boyde \& Rahmatullah (1980). The supernatant was mixed with a $1 \mathrm{ml}$ aliquot of chromogenic solution ( $16.7 \%$ sulphuric acid, $0.05 \%$ butanedione monoxime, $0.01 \%$ thiosemicarbazide). The samples were boiled for $5 \mathrm{~min}$, cooled to room temperature in the dark and $\mathrm{OD}_{530}$ was measured. One unit $(\mathrm{U})$ of enzyme activity was defined as the amount of enzyme that was required for converting $1 \mu \mathrm{M}$ substrate into $1 \mu \mathrm{M}$ product $\min ^{-1}$ under the assay conditions. Citrulline or $\mathrm{N}$-carbamoylputrescine standard was included as a positive control and the enzyme was added into solution A containing $50 \mu \mathrm{l} 50 \% \mathrm{TCA}$ as a negative control.

Determination of in vitro anabolic ornithine and putrescine carbamoyltransfer activities. The reaction was initiated by adding $0.5 \mu \mathrm{M}$ purified Lmo0036 into solution B (4 mM ornithine or putrescine, $4 \mathrm{mM}$ carbamoylphosphate, $20 \mathrm{mM}$ Tris/ $\mathrm{HCl}, \mathrm{pH} 4.0$ 11.0 ) and stopped at the indicated time points by adding $50 \mu \mathrm{l} 50 \%$
TCA. This reaction was conducted at $37^{\circ} \mathrm{C}$. The enzyme activity was measured as shown above, based on the production of citrulline or $N$ carbamoylputrescine.

Analysis of biogenic amine by ultraperformance liquid chromatography (UPLC) combined with electrospray ionization tandem mass spectrometry (MS-MS). Analysis of biogenic amine (citrulline, ornithine, carbamoylputrescine or putrescine) in reaction samples was performed by UPLC-MS-MS with electrospray positive ionization (ESI +) as in previous studies (Ren et al., 2007; Wu et al., 2006). Briefly, an ACQUITY UPLC quaternary pump system equipped with the micro vacuum degasser, thermostat-equipped autosampler and thermostat-equipped column compartment (Waters) was coupled with a Micromass Quattro Ultima triple-quadrupole mass spectrometer. The analyte elution was carried out on a UPLC BEH C18 column (150 mm length, $2.0 \mathrm{~mm}$ internal diameter, $3.5 \mu \mathrm{m}$ particle size; Waters) maintained at $25{ }^{\circ} \mathrm{C}$ with a run time of $3 \mathrm{~min}$. The mobile phase was $10 \%$ methanol: $0.1 \%$ formic acid in water with a flow rate of $0.2 \mathrm{ml} \mathrm{min}{ }^{-1}$. The conditions used for the electrospray source were as follows: capillary voltage, $3.5 \mathrm{kV}$; cone voltage, $50 \mathrm{~V}$; source temperature, $100{ }^{\circ} \mathrm{C}$; desolvation gas temperature, $350{ }^{\circ} \mathrm{C}$; desolvation gas flow, 4001 nitrogen $\mathrm{h}^{-1}$; cone gas flow, 451 nitrogen $\mathrm{h}^{-1}$; argon collision gas pressure to $3 \times 10^{-3}$ mbar for MS-MS. The collision energy was optimized for each multiple reaction monitored transition.

Determination of ammonia in the culture supernatant. Production of ammonia in L. monocytogenes strain $10403 \mathrm{~S}$ and its respective mutants, $\Delta \operatorname{lmo} 0036$ and $\Delta \operatorname{lmo} 0036+\operatorname{lmo} 0036$, was measured by using the Ammonia Assay kit (Sigma) using a modified version of the method of Fulde et al. (2011). For this, bacteria were grown in trypticase soya broth with yeast extract (TSBY) medium and harvested by centrifugation $24 \mathrm{~h}$ after inoculation. The amount of ammonia $\left(\mathrm{mg} \mathrm{ml}^{-1}\right)$ in the supernatant was determined according to the manufacturer's instructions. The ammonia production in the parent strain was set at $100 \%$.

Quantitative reverse transcriptase PCR. L. monocytogenes strain $10403 \mathrm{~S}$ was grown in $\mathrm{BHI}$ to stationary phase $\left(\mathrm{OD}_{600} 0.6\right)$. The culture was divided into two portions: one was exposed to sublethal acidic conditions ( $\mathrm{pH} 4.8)$ and the other to neutral conditions ( $\mathrm{pH} 7.0)$. After 60 min exposure, bacterial cells were collected by centrifugation and subjected to total RNA extraction using a Trizol extraction kit according to the manufacturer's instructions. DNase I (Fermentas) digestion was performed to break down contaminating genomic DNA. The resulting DNA-free RNA was converted to cDNA using Reverse Transcriptase (Promega). The concentration and purity of cDNA were evaluated by using a Nanodrop ND-1000 spectrophotometer.

The quantitative real-time PCR (qRT-PCR) was performed using an iCycler $\mathrm{iQ}$ real-time PCR detection system (Bio-Rad Laboratories) and a SYBR Premix Ex Taq (perfect real-time) PCR kit (TaKaRa) with primers listed in Table 1. Imo0036 was cloned into pMD18-T and a 10 -fold dilution series of the recombinant plasmid was used to

Table 2. Mutations in active sites of Lmo0036 by site-directed mutagenesis

\begin{tabular}{|llll|}
\hline $\begin{array}{l}\text { Amino acid } \\
\text { position }\end{array}$ & Putative function & Substitution & Primer \\
\hline $54-58$ & Carbamoyl phosphate binding & STRTR $\rightarrow$ AAAAA & $\begin{array}{r}\text { TTGAACAATCAGCAGCAGCAGCAGCAGTATCTTTTGAAACAGCA } \\
\text { TGCTGTTTCAAAAGATACTGCTGCTGCTGCTGCTGATTGTTCAA }\end{array}$ \\
105 & Carbamoyl phosphate binding & $\mathrm{R} \rightarrow \mathrm{A}$ & $\begin{array}{r}\text { TGAAGTTTATGGCCGCAGCAGCCGCAACTCGTGGGGAA } \\
\text { TTCCCCACGAGTTGCGGCTGCTGCGGCCATAAACTTCA }\end{array}$ \\
$271-274$ & Putrescine/ornithine binding & HCLP $\rightarrow$ AAAA & $\begin{array}{r}\text { ATATTGATGGCGGCAGTTGAACGTCATCAA } \\
\text { TTGATGACGTTCAACTGCCGCCATCAATAT }\end{array}$ \\
& & & \\
\end{tabular}


construct a standard curve for qRT-PCR. The transcriptional levels of 1 mo0036 were calculated based on the standard curve. The housekeeping gene gyrB was selected as the reference gene for normalization (Table 1). RNA was extracted from three separate cultures and all qRT-PCRs were performed in triplicate (E value $>0.99$ ). The transcription level of $l m o 0036$ at pH 7.0 was set as $100 \%$.

Growth in sublethal acidic conditions. L. monocytogenes strains $10403 \mathrm{~S}$ and $\Delta \mathrm{lmo} 0036$ were cultured to stationary phase $\left(\mathrm{OD}_{600} 0.6\right)$, washed in PBS $(0.01 \mathrm{M}, \mathrm{pH} 7.2)$ and $1: 100$ diluted in BHI adjusted to $\mathrm{pH}$ 4.8. Samples $(200 \mu \mathrm{l})$ were removed and added to individual wells of a 96-well plate. Growth at $37{ }^{\circ} \mathrm{C}$ was measured at $\mathrm{OD}_{600}$ for $12 \mathrm{~h}$. This experiment was repeated three times, in triplicate wells for each strain.

To further determine the role of Lmo0036 in listerial growth under acidic conditions, a competitive growth experiment was performed as previously reported (Milillo et al., 2009). Briefly, stationary phase cultures of $10403 \mathrm{~S}$ and $\Delta \mathrm{lmo} 0036$ were mixed in a $1: 1$ ratio, followed by $1: 100$ dilution into $\mathrm{BHI}$ at $\mathrm{pH} 4.8$. A 10-fold dilution series of the mixed cultures was plated onto BHI plates at two time points corresponding to mid-exponential and stationary phases (i.e. 6 and $12 \mathrm{~h}$ after inoculation). At each time point, 40 colonies were subjected to PCR analysis to identify colonies as the mutant or parent strain using primers $36-\mathrm{a} / 36-\mathrm{d}$ (Table 1). This assay was run in triplicate three times.

Survival in synthetic gastric fluid. Stationary phase cultures of $L$. monocytogenes $10403 \mathrm{~S}$ and its mutant $\Delta \mathrm{lmo0036}$ were harvested, washed in PBS and resuspended in synthetic human gastric fluid (8.3 g proteose peptone, $3.5 \mathrm{~g}$ D-glucose, $2.05 \mathrm{~g} \mathrm{NaCl}$, $0.6 \mathrm{~g} \mathrm{KH}_{2} \mathrm{PO}_{4}$, $0.11 \mathrm{~g} \mathrm{CaCl}_{2}, 0.37 \mathrm{~g} \mathrm{KCl}, 0.05 \mathrm{~g}$ bile, $0.1 \mathrm{~g}$ lysozyme and $13.3 \mathrm{mg}$ pepsin, all $\left.1^{-1} ; \mathrm{pH} 2.5\right)$. Changes in the cell population were determined by plate counting after $30 \mathrm{~min}$ of incubation. The test was run in triplicate three times.

Mouse virulence assays. The virulence of $\Delta \mathrm{lmo} 0036$ and its parent strain $10403 \mathrm{~S}$ was assessed using ICR mice (female, $20 \mathrm{~g}$ ) as described previously (Jiang et al., 2011). The animal experiment was approved by the Laboratory Animal Management Committee of Zhejiang University and mice were handled under strict ethical conditions. Briefly, five groups (six per group) of mice were inoculated intraperitoneally with $0.2 \mathrm{ml}$ aliquots of the appropriately diluted Listeria strain resuspended in PBS. Mice in the control group received injections of PBS. The group inoculated with appropriately $5 \times 10^{5}$ bacterial cells were killed 3 days post-infection. Spleens were homogenized in PBS (0.01 M, pH 7.2) and surviving cells enumerated by plating serial dilutions of the homogenized organs on $\mathrm{BHI}$ agar. The $\mathrm{LD}_{50}$ values were calculated by using the trimmed Spearman-Karber method on the basis of mouse mortality data recorded during a 10 day post-injection period.

Statistical analysis. The two-tailed Student's $t$-test was used for comparison of data, where necessary, and $P$-values $\leqslant 0.05$ were considered statistically significant.

\section{RESULTS}

\section{Lmo0036 is conserved in L. monocytogenes lineages I and II}

Imo0036 was highly conserved in L. monocytogenes lineages I and II strains with $99 \%$ sequence identity at the amino acid level. Imo0036 showed higher similarity to its orthologues in other bacteria, including members of the genera Streptococcus, Enterococcus, Pediococcus, Lactobacillus and Lactococcus (64.6-74.5\%), than to those in Mycoplasma (49.6-51.0\%) (Fig. 2a). Lmo0036 and its orthologues shared the same conserved motif and residues, including sites for substrate binding and for structural integrity (Fig. 2b), suggesting that Lmo0036 is a typical carbamoyltransferase containing intact functional residues.

\section{Expression and purification of Lmo0036}

To analyse the enzyme activity of Lmo0036, Imo0036 was overexpressed in E. coli Rosetta following IPTG induction. The majority of the expression product was in soluble form and only a small portion was formed as inclusion bodies (Fig. 3a). His-tagged recombinant Lmo0036 was purified to homogeneity by nickel-chelated affinity column chromatography. Its purity was confirmed by SDS-PAGE as indicated by a single band at the expected molecular mass (Fig. 3b).

\section{Lmo0036 catalyses reversible in vitro ornithine carbamoyltransfer reactions}

The in vitro catabolic and anabolic ornithine carbamoyltransfer activities of Lmo0036 were tested using citrulline and ornithine as substrates respectively. The ornithine carbamoyltransfer activities varied at different $\mathrm{pHs}$, the catabolic direction peaked under acidic conditions with an optimal $\mathrm{pH}$ of 5.0-6.0 (Fig. 4a) and the anabolic direction was highest under alkaline conditions with an optimal $\mathrm{pH}$ of 10.0 (Fig. 4b). Lmo0036 exhibited significantly higher specific activity of anabolic ornithine carbamoyltransferase (aOTC) (3.59 U $\left.\mathrm{mg}^{-1}\right)$ than that of cOTC $\left(0.12 \mathrm{U} \mathrm{mg}^{-1}\right)$ (Table 3). The reaction products, ornithine or citrulline, were confirmed by UPLC-MS-MS analysis (data not shown). These results indicate that Lmo0036 acts as an OTC catalysing reversible ornithine carbamoyltransfer reactions.

Less than $18 \%$ of the aOTC activity of variant Lmo0036 proteins, harbouring mutations in positions $54-58$ $($ STRTR $\rightarrow$ AAAAA $), 105(\mathrm{R} \rightarrow \mathrm{A})$ and $271-274(\mathrm{HCLP} \rightarrow$ AAAA) (Table 2), were retained at $\mathrm{pH} 5.0(P<0.01)$ (Fig. $5 \mathrm{a})$, demonstrating that these sites were crucial for the ornithine carbamoyltransferase (OTC) activity.

\section{Lmo0036 mediates reversible in vitro putrescine carbamoyltransfer reactions}

The in vitro catabolic and anabolic putrescine carbamoyltransfer (aPTC) activities of Lmo0036 were determined using carbamoylputrescine and putrescine as substrates, respectively. Putrescine carbamoyltransfer activities varied with $\mathrm{pH}$, with catabolic activity being highest under acidic condition with an optimal pH of 5.0 (Fig. 4c) and anabolic activity highest under alkaline condition at $\mathrm{pH} 8.0$ (Fig. 4d). This enzyme showed significantly higher specific activity of aPTC $\left(35.60 \mathrm{U} \mathrm{mg}^{-1}\right)$ than that of cPTC $\left(0.57 \mathrm{U} \mathrm{mg}^{-1}\right)$ (Table 3 ). The reaction products, putrescine or carbamoylputrescine, were confirmed by HPLC-MS-MS analysis (data not shown). These data illustrate that Lmo0036 also acts as a putrescine carbamoyltransferase (PTC) catalysing reversible putrescine carbamoyltransfer reactions. 


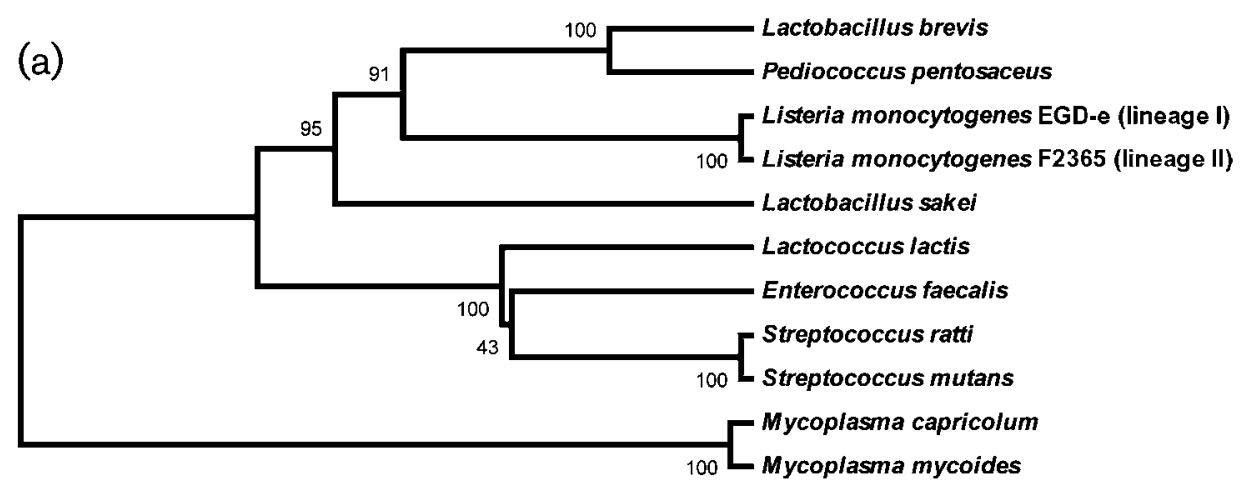

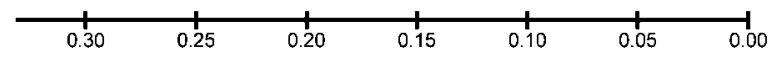

(b)

Listeria monocytogenes EGD-e Listeria wonocytogenes F2365 Enteracoccus faecalis Theroccus faecalis Lactobacillus brevis Lactobacillus sare1 Pediocaccus pentosaceus Pediococcus pentosace streptococcus mutans treptococcus ratti Mycoplasma capricolun

Listeria monocytogenes EGD-e Listeria monocycogenes $\$ 2365$ Enteracoccus faecalis Lactobacillus brevis Lactobacillus sakei Lactococous Lactis Pediococcus pentosaceus Streptococcus mutans streptococcus ratti Yycoplasoa capricolu Mycoplasua mycoides

Listeria monocytogenes EGD-e Listeria monocytagenes F2365 Enterococcus faecalis Lectobacillus brevis Lactobacillus sake Lactococcus lactis Pediococcus pentosaceus streptacoccus nutans streptococcus ratti MYcoplasma capricolun Mycoplasma mycoides

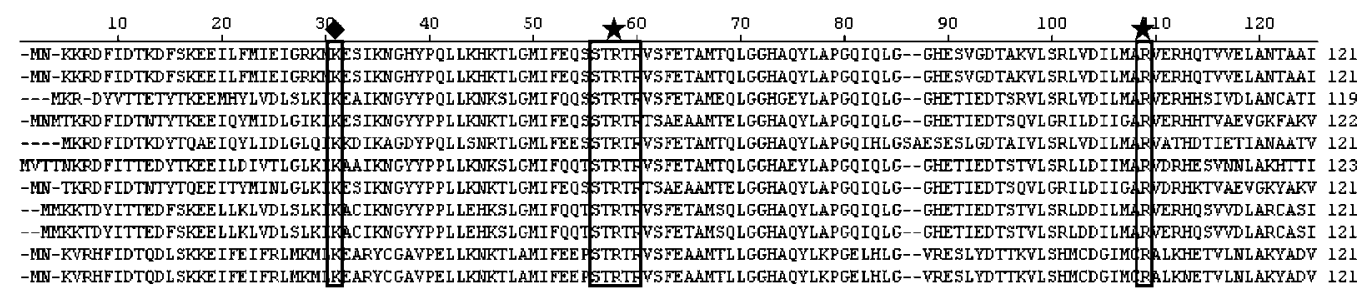$$
130+140 \quad-160 \quad 130 \quad-180 \quad-190 \quad 200 \quad 210 \quad 230 \quad 230 \quad 240
$$

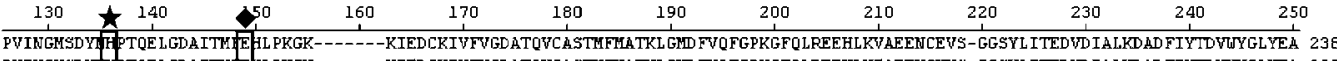



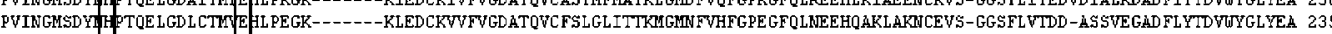

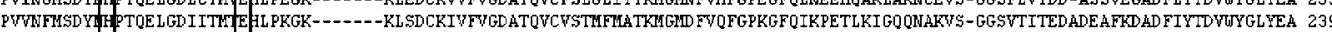
PULEGMTDY 1 TQTEIGDIITM

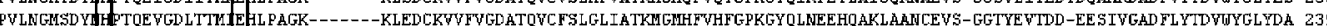

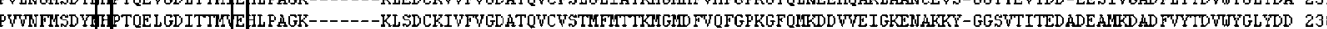

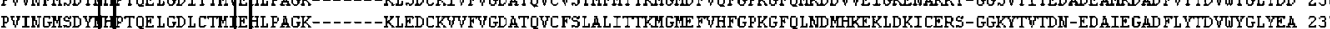

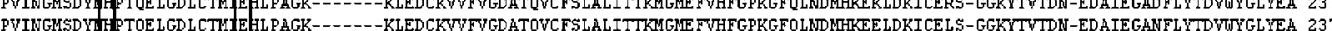

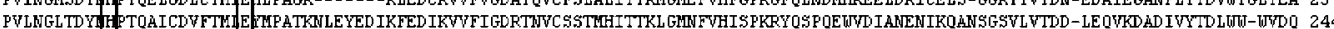

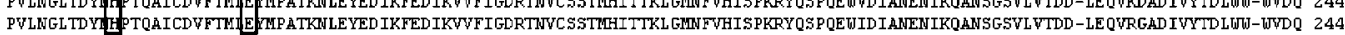

$\begin{array}{lllllll}260 & 270\end{array}$

Fig. 2. (a) Phylogenetic tree of Lmo0036 and its homologues from diverse bacterial species. The values above and below the horizontal lines (expressed as percentages) indicate the robustness of the corresponding branches, as determined by a bootstrap analysis evaluated from 1000 replications. (b) Conserved motifs and residues among bacterial species are boxed. Residues required for carbamoylphosphate $\left({ }^{\star}\right)$ and putrescine/ornithine $(\boldsymbol{\square})$ binding and for structural integrity $(\boldsymbol{})$ are indicated above the alignment.

On the other hand, the aPTC activity of variant Lmo0036 proteins, containing mutations in positions $54-58$ (STRTR $\rightarrow$ AAAAA), $105(\mathrm{R} \rightarrow \mathrm{A})$ and 271 to $274(\mathrm{HCLP} \rightarrow \mathrm{AAAA})$ (Table 2), decreased to significantly lower levels when incubated at $\mathrm{pH} 5.0(P<0.01)$ (Fig. 5b), indicating that these sites were also critical for the PTC reactivity.

\section{Deletion of Imo0036 leads to a loss in ammonia production}

Since Lmo0036 is speculated to be a carbamoyltransferase participating in ADI and AgDI pathways which play a role in acid tolerance via ammonia generated in the first and third steps (Fig. 1a, b, e), production of ammonia was monitored in L. monocytogenes $10403 \mathrm{~S}$ and its mutants $\Delta \mathrm{lmo} 0036$ and $\Delta \mathrm{lmo} 0036+\mathrm{lmo} 0036$. Ammonia production displayed a $40 \%$ decrease in $\Delta \operatorname{lmo} 0036$ compared with its parent strain and complemented strain $(P<0.01)$, indicating an important role of Lmo0036 in bacterial ammonia production.

\section{Transcriptional analysis of Imo0036 under acidic conditions}

As the ADI or AgDI pathway confers a possible contribution to bacterial acid tolerance, alterations in expression of 

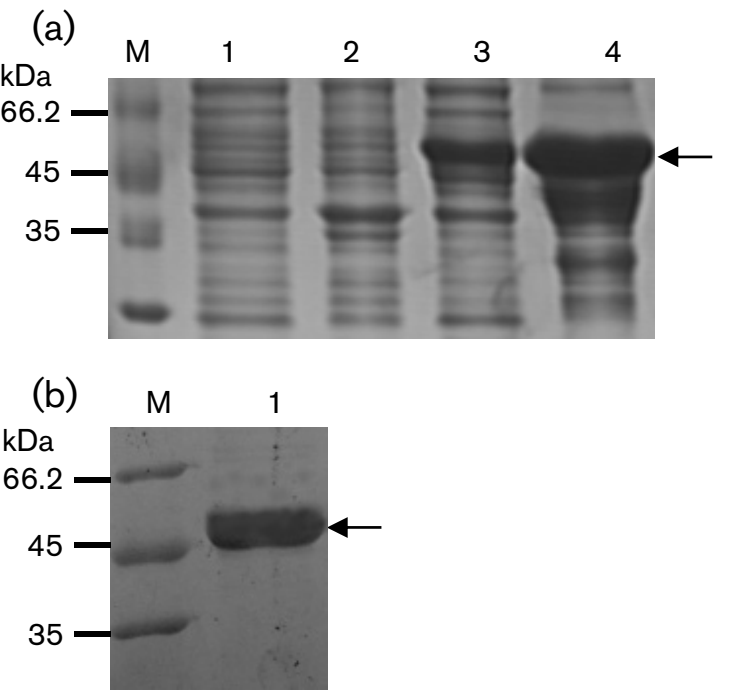

Fig. 3. SDS-PAGE analysis of the recombinant Lmo0036 protein. (a) Expression of Lmo0036. Lanes: M, molecular mass standards; 1, inclusion body of $E$. coli Rosetta harbouring pET30a; 2, supernatant of $E$. coli Rosetta harbouring $\mathrm{pET} 30 \mathrm{a}$; 3 , inclusion body of $E$. coli Rosetta harbouring pET30a-Imo0036; 4, supernatant of $E$. coli Rosetta harbouring pET30a-Imo0036. (b) Purification of Lmo0036. Lanes: M, molecular mass standards; 1 , E. coli Rosetta harbouring pET30a-Imo0036.
Imo0036 of L. monocytogenes $10403 \mathrm{~S}$ under acidic conditions were examined by qRT-PCR. Expression of $1 m o 0036$ showed around a fourfold increase under acidic conditions $(\mathrm{pH} 4.8)$, compared with that under neutral conditions $(\mathrm{pH} 7.0) \quad(P<0.01)$, suggesting a possible role of the Imo0036 gene product in acid adaptation.

\section{$\Delta$ Imo0036 exhibits slower growth under sublethal acidic conditions}

The mutant $\Delta \operatorname{lmo} 0036$ exhibited a similar growth rate to its parent strain in BHI at neutral $\mathrm{pH} 7.0$ (data not shown), indicating that $1 m 00036$ was not essential for listerial growth under normal conditions. Exposure to sublethal acidic conditions ( $\mathrm{pH} 4.8$ ) resulted in a significant reduction $(P<0.05)$ in growth rate and in final optical densities of $\Delta \mathrm{lmo} 0036$ relative to its parent strain and complemented strain (Fig. 6a).

To more sensitively determine the role of Lmo0036 in acid tolerance under sublethal acidic conditions, competitive growth experiments were performed in BHI adjusted to $\mathrm{pH}$ 4.8. Significantly lower numbers of $\Delta \mathrm{lmo} 0036$ were recovered at both the mid-exponential and early stationary phase time points $(P<0.05)$ (Fig. 6b), indicating that Lmo0036 contributed to enhanced acid tolerance under mildly (sublethal) acidic conditions. (a)

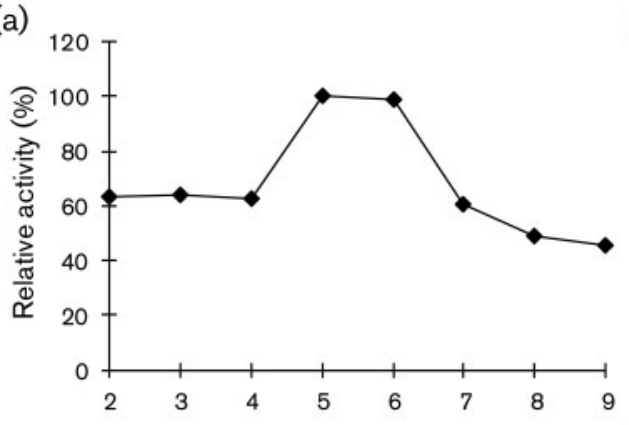

(c)



(b)

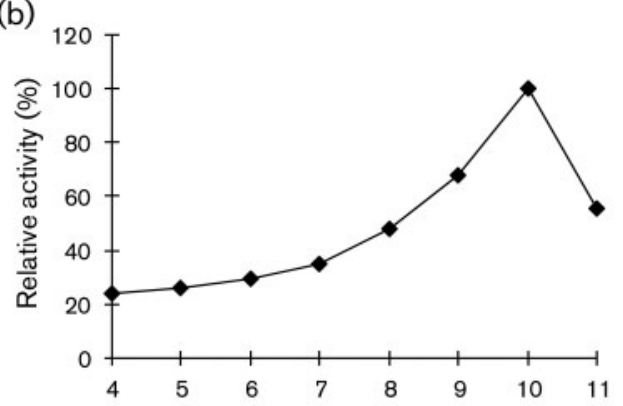

(d)



Fig. 4. Relative enzymic activities of purified $\mathrm{Lmo0036}$ under different pHs measured after 60 min of incubation. (a) Catabolic ornithine carbamoyltransfer activity. (b) Anabolic ornithine carbamoyltransfer activity. (c) Catabolic putrescine carbamoyltransfer activity. (d) Anabolic putrescine carbamoyltransfer activity. The peak values of the four carbamoyltransfer activities were set at $100 \%$. 
Table 3. Optimal $\mathrm{pH}$ and specific activity $\left(\mathrm{U} \mathrm{mg}^{-1}\right)$ of Lmo0036 in L. monocytogenes

\begin{tabular}{|lccc|}
\hline & Direction & $\begin{array}{c}\text { Optimal } \\
\mathbf{p H}\end{array}$ & $\begin{array}{c}\text { Specific } \\
\text { activity } \\
\left(\mathbf{U ~ m g}^{-1}\right)\end{array}$ \\
\hline $\begin{array}{l}\text { Ornithine } \\
\text { carbamoyltransferase } \\
\text { (OTC) }\end{array}$ & Catabolic & $5.0-6.0$ & 0.12 \\
$\begin{array}{l}\text { Putrescine } \\
\text { carbamoyltransferase } \\
\text { (PTC) }\end{array}$ & Catabolic & 10.0 & 3.59 \\
\hline & Anabolic & 8.0 & 0.57 \\
& & & 35.60 \\
\hline
\end{tabular}

\section{$\Delta$ Imo0036 shows decreased survival ability in lethal acidic conditions}

To clarify the contribution of Lmo0036 to the survival of $L$. monocytogenes at lethal $\mathrm{pH}$, survival was examined in synthetic human gastric fluid adjusted to $\mathrm{pH} 2.5$. The $\Delta$ lmo0036 mutant exhibited a 10 -fold reduction in the survival rate compared with the parent strain and complemented strain $(P<0.01) \quad$ (Fig. 6c), suggesting that Lmo0036 is involved in the acid resistance of $L$. monocytogenes under potentially lethal $\mathrm{pH}$ conditions.
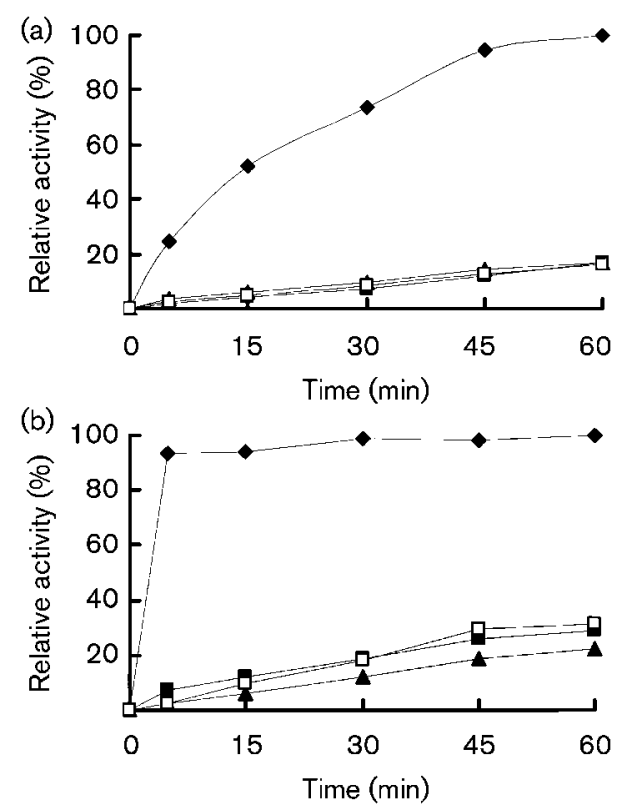

Fig. 5. Relative enzyme activities of wild-type and recombinant variant $\mathrm{Lmo0036}$ proteins measured at the indicated time points. (a) Anabolic ornithine carbamoyltransfer reactivity. (b) Anabolic putrescine carbamoyltransfer reactivity. The peak values of carbamoyltransfer activities of wild-type Lmo0036 were set at $100 \%$. (a, b) . Lmo0036; $\mathbf{\square}$, Lmo0036-R105A; $\boldsymbol{\Delta}$, Lmo0036STRTR54 58AAAAA; $\square$, Lmo0036-HCLP271 247AAAA.

\section{Lmo0036 is implicated in the virulence of L. monocytogenes}

To examine whether the reduced acid tolerance of $L$. monocytogenes results in impaired bacterial in vivo virulence, we calculated the $\mathrm{LD}_{50}$ values and enumerated the surviving cells in the spleens 3 days post-infection in an intraperitoneally inoculated murine model. $\mathrm{LD}_{50}$ of $\Delta \mathrm{lmo} 0036$ ( $\mathrm{LD}_{50} \sim 6.2 \times 10^{5}$ c.f.u.) was found to be higher than that of its parent strain $\left(\mathrm{LD}_{50} \sim 8.5 \times 10^{4}\right.$ c.f.u. $)$ and complemented strain $\left(\mathrm{LD}_{50} \sim 7.8 \times 10^{4}\right.$ c.f.u.). Also, $\Delta \mathrm{lmo} 0036$ exhibited an approximately 16 -fold decrease in survival in the spleen relative to its parent strain and an 11-fold decrease relative to the complemented strain $(P<0.05)$ (Fig. 6d), indicating that deletion of Lmo0036 influences the ability of $L$. monocytogenes to cause invasive disease in mice.

\section{DISCUSSION}

Acid represents one of the most frequently encountered stresses for foodborne pathogens, including L. monocytogenes (Bowman et al., 2010; Cotter \& Hill, 2003). The ability to survive and grow to high numbers in acidic environments is critical for L. monocytogenes to initiate systemic infection (Sleator et al., 2009). Thus, it is important to understand the mechanisms which L. monocytogenes utilizes to overcome this hurdle, which might in turn point to strategies for controlling this pathogen in foods. The glutamate decarboxylase (GAD) system plays a role in L. monocytogenes survival at low pH (Cotter et al., 2001) and the ADI and AgDI systems encoded by lmo0036-lmo0043 may also contribute to stabilizing the cytoplasmic $\mathrm{pH}$ in L. monocytogenes (Chen et al., 2009d; Ryan et al., 2009). Ryan et al. (2009) identified that functional ADI (encoded by lmo0043) has a role in initiating the ADI pathway. Chen et al. (2009d) also determined the role of AgDI (encoded by lmo0038) in acid stress response, which triggers the putative AgDI pathway. It is tempting to speculate that functional ADI and AgDI systems work in parallel in L. monocytogenes.

\section{Lmo0036 represents the first example of a carbamoyltransferase which is able to catalyse reversible ornithine and putrescine carbamoyltransfer reactions}

OTC is widely distributed in Gram-positive and Gramnegative bacteria and comprises two subtypes, aOTC and cOTC (Arena et al., 2002; Casiano-Colón \& Marquis, 1988; Legrain \& Stalon, 1976; Sainz et al., 1998). aOTC catalyses the carbamoylation of ornithine to form citrulline participating in de novo biosynthesis of arginine, while cOTC performs the decarbamoylation of citrulline to form ornithine and carbamoylphosphate, which represents the second step of the ADI pathway (Cunin et al., 1986; Legrain \& Stalon, 1976) (Fig. 1c). Members of the genera Pseudomonas, Aeromonas, Proteus and Enterococcus possess two distinct enzymes, aOTC (encoded by $\arg F$ ) and cOTC (encoded by $\operatorname{arcB}$ ), catalysing the anabolic or catabolic 

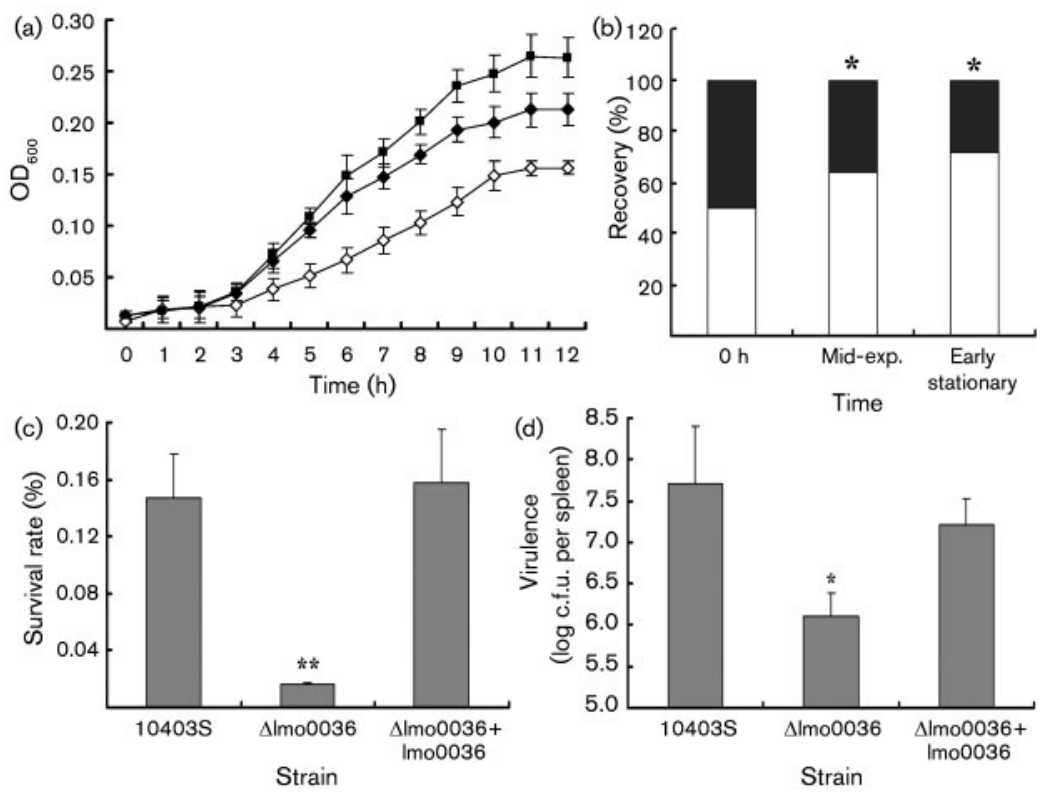

Fig. 6. Growth and survival of $L$. monocytogenes 10403S $(\nabla)$ and its mutant strains $\Delta \mathrm{lmo0036}(\diamond)$ and $\Delta \mathrm{lmo0036}+\mathrm{Imo0036}(\mathbf{\square})$ under acidic conditions in vitro and in mice. (a) Growth of the L. monocytogenes strains in brain heart infusion $(\mathrm{BHI})$ under sublethal acidic conditions ( $\mathrm{pH}$ 4.8). (b) Competitive growth of the parent strain (white) and $\Delta$ Imo0036 (black) in $\mathrm{BHI}$ under sublethal acidic conditions $(\mathrm{pH} 4.8)$ as shown by respective percentages in the mixture. (c) Survival of the L. monocytogenes strains in synthetic human gastric fluid $(\mathrm{pH} 2.5)$. (d) Comparison of virulence of the $L$. monocytogenes strains in ICR mice. Bars indicate the numbers of $L$. monocytogenes cells recovered from the spleens 3 days post-infection. Error bars indicate SD. ${ }^{*} P<0.05 ;{ }^{*} P<0.01$. reaction, respectively (De la Fuente et al., 1996). E. coli $\mathrm{K}-12$ harbours two genes, $\arg F$ and $\operatorname{argI}$, encoding two homologues of aOTC (Cunin et al., 1986). Notably, aOTC is also able to catalyse the cOTC reaction in the majority of bacterial genera except Pseudomonas, whilst cOTC fails to mediate and, in some cases, even represses in vivo anabolic activity (Cunin et al., 1986; Sainz et al., 1998).

Relatively less is known about PTC. This enzyme has only been identified in a small number of bacteria (Llácer et al., 2007; Lucas et al., 2007). PTC and OTC both belong to the aspartate carbamoyltransferase/OTC (ATC/OTC) family. At least two differences are found between these two carbamoyltransferases. First, PTC possesses both anabolic and catabolic activities in most cases (Wargnies et al., 1979) (Fig. 1d). The catabolic reaction represents the second step of the AgDI pathway (Lucas et al., 2007). Second, in contrast with OTC being substrate-specific, PTC utilizes a wide range of substrates other than putrescine, including ornithine and several diamines (diaminopropane, diaminohexane, spermine, spermidine, cadaverine). However, specific activities of PTC using these alternative substrates are apparently lower (Wargnies et al., 1979).

Determination of the carbamoyltransferase activities usually relies on isotopic tracing and NMR methods (Legrain \& Stalon, 1976; Sainz et al., 1998). These approaches are complicated, time-consuming and less visual. Thus, we used biochemical-coloration reactions combined with UPLCMS-MS analysis to provide convincing evidence for the enzymic activities of Lmo0036. Generation of ornithine or putrescine is determined based on the production of a red colour (catabolic), while consumption of citrulline or carbamoylputrescine is linked to the colour turning lighter pink (anabolic). Kinetic studies revealed that the equilibrium of in vitro ornithine or putrescine carbamoyltransfer reactions lies overwhelmingly towards the formation of citrulline or carbamoyl (anabolic) (Legrain \& Stalon, 1976; Legrain et al., 1977; Sainz et al., 1998).

The lmo0036-lmo0043 cluster in L. monocytogenes represents the first example, to our knowledge, of ADI and AgDI systems at the same genetic locus (Chen, 2010). $\operatorname{lmo0036}$ is the first gene in this cluster upstream of 1 mo0043 (ADI) and $1 m 00038$ (AgDI), and encodes the only putative carbamoyltransferase therein (Fig. 2). Lmo0036 contains the conserved motif and residues, including sites for substrate binding and for structural integrity (Fig. 2b; Fig. 5), suggesting that Lmo0036 is a typical carbamoyltransferase. This enzyme represents the first example, to our knowledge, of carbamoyltransferase catalysing reversible ornithine and putrescine carbamoyltransfer reactions (Fig. 4). It exhibited higher in vitro specific activities of aOTC and aPTC than those of cOTC and CPTC (Table 3), consistent with previous reports that in vitro OTC or PTC reactions lie towards the anabolic direction (Legrain \& Stalon, 1976; Legrain et al., 1977; Sainz et al., 1998).

\section{Lmo0036 promotes ADI and AgDI pathways and mediates acid tolerance}

ADI deiminates the substrate arginine producing citrulline and $\mathrm{NH}_{3}$ (Fig. 1a). Citrulline is phosphorylated from phosphate $(\mathrm{Pi})$ by cOTC, yielding carbamoylphosphate and ornithine (Fig. 1c) (Cunin et al., 1986; Vrancken et al., 2009b). On the other hand, AgDI initiates its pathway via deimination of agmatine generating carbamoylputrescine and $\mathrm{NH}_{3}$ (Fig. 1b). Carbamoylputrescine is phosphorylated from phosphate by CPTC producing carbamoylphosphate and putrescine (Fig. 1d) (Landete et al., 2008; Llácer et al., 2007). The final reactions of both ADI and AgDI pathways require $\mathrm{CK}$ with the end products $\mathrm{ATP}, \mathrm{CO}_{2}$ and $\mathrm{NH}_{3}$ from 
carbamoylphosphate (Fig. 1e) (Ramón-Maiques et al., 2010). For each mole of arginine or agmatine catabolized via the deiminase pathway, two moles of ammonia are produced. The ammonia can combine with intracellular cytoplasmic protons to yield ammonium ions $\left(\mathrm{NH}_{4}{ }^{+}\right)$, thereby alleviating acidification of the cytoplasm and contributing to $\mathrm{pH}$ homeostasis (Cunin et al., 1986). Thus, ADI and AgDI pathways have been proposed to be important for acid stress response. ADI or AgDI, catabolic carbamoyltransferase and $\mathrm{CK}$ represent three important enzymes responsible for the pathways. As ADI or AgDI catalyses an essentially irreversible reaction and, also, as the reaction mediated by $\mathrm{CK}$ is significantly in favour of ATP synthesis, catabolic carbamoyltransferase is probably the limiting step of the pathway (Legrain \& Stalon, 1976; Legrain et al., 1977). Kinetic studies supported this hypothesis; we observed that specific activities of cOTC and CPTC are considerably lower than those of aOTC and aPTC (Table 3).

The gene $1 m o 0036$ is induced at the transcriptional level under low $\mathrm{pH}$ and its product Lmo0036 exhibits significantly higher COTC and CPTC activities under acidic conditions (Fig. 4a, c; Table 3), suggesting that Lmo0036 is a critical enzyme that is required for the acid tolerance systems. Subsequently, we examined the role of Lmo0036 using an Imo0036 knockout mutant and its complemented mutant. Absence of this enzyme impairs the growth of $L$. monocytogenes in BHI under mild acidic condition ( $\mathrm{pH} 4.8$ ) (Fig. 6a, b) and also attenuates the survival ability in synthetic human gastric fluid ( $\mathrm{pH}$ 2.5) (Fig. 6c), which corresponds to a decrease in ammonia production $(P<0.01)$. These results consistently illustrate that deletion of Lmo0036 inactivates the ADI and AgDI pathways, which are required for maximal acid tolerance at both sublethal and lethal $\mathrm{pH}$ levels. The first step (a deimination reaction producing $1 \mathrm{~mol}$ ammonia) of the ADI and AgDI pathways mediated by $\mathrm{ADI}$ and $\mathrm{AgDI}$ is apparently functional in $\Delta$ lmo0036. However, accumulation of the product, citrulline or carbamoylputrescine, might affect the reaction equilibrium, thereby leading to a decreased efficiency of the deimination reaction and reduced generation of ammonia.

The ability to tolerate or resist acid stress has been implicated in the virulence potential of a number of bacteria (Ryan et al., 2009; Sainz et al., 1998). The acidtolerant $L$. monocytogenes strains are more invasive in vitro (Conte et al., 2000) and more virulent in vivo (O'Driscoll et al., 1996) than their acid-sensitive counterparts, and the reverse has also been established. Consistently, a mutant unable to induce acid tolerance response displays subdued virulence compared with its parent strain in mice (Marron et al., 1997). This is also the case for $\Delta \operatorname{lmo0036}$, although absence of Lmo0036 did not affect the in vitro invasive ability in HeLa epithelial cells (data not shown), but impaired the in vivo virulence in mice (Fig. 6d). In addition, $l m o 0036$ is conserved in L. monocytogenes lineages I and II and another pathogenic species Listeria ivanovii, but is absent from non-pathogenic species (Listeria innocua, Listeria welshimeri and Listeria seeligeri) and also specifically absent from L. monocytogenes lineages III and IV, which appear to be rarely associated with human morbidity (Chen et al., 2009c, 2010b; Orsi et al., 2011; Ward et al., 2008), further suggesting that this enzyme is involved in the pathogenesis of L. monocytogenes, most likely by its acid tolerance mechanisms.

In conclusion, L. monocytogenes harbours a functional Lmo0036 catalysing reversible ornithine and putrescine carbamoyltransfer reactions. This enzyme promotes ADI and AgDI pathways that contribute to the acid tolerance and virulence of the bacterium. Lmo0036 represents, to our knowledge, the first enzyme involved in the ADI and AgDI pathways in L. monocytogenes to be reported.

\section{ACKNOWLEDGEMENTS}

This work is supported by National Natural Science Foundations of China (31101829 and 30870068) and the Key Project of National Science \& Technology Pillar Programme (2009BADB9B09). J.C. is supported by the China Postdoctoral Science Foundation (20100481428). We thank Dr Dongyou Liu (Royal College of Pathologists of Australian Quality Assurance Programs, Sydney, Australia) and Dr John Bowman (University of Tasmania, Australia) for helpful discussions.

\section{REFERENCES}

Arena, M. E., Manca de Nadra, M. C. \& Muñoz, R. (2002). The arginine deiminase pathway in the wine lactic acid bacterium Lactobacillus hilgardii X1B: structural and functional study of the arcABC genes. Gene 301, 61-66.

Bowman, J. P., Lee Chang, K. J., Pinfold, T. \& Ross, T. (2010). Transcriptomic and phenotypic responses of Listeria monocytogenes strains possessing different growth efficiencies under acidic conditions. Appl Environ Microbiol 76, 4836-4850.

Boyde, T. R. \& Rahmatullah, M. (1980). Optimization of conditions for the colorimetric determination of citrulline, using diacetyl monoxime. Anal Biochem 107, 424-431.

Byelashov, O. A., Daskalov, H., Geornaras, I., Kendall, P. A., Belk, K. E., Scanga, J. A., Smith, G. C. \& Sofos, J. N. (2010). Reduction of Listeria monocytogenes on frankfurters treated with lactic acid solutions of various temperatures. Food Microbiol 27, 783-790.

Casiano-Colón, A. \& Marquis, R. E. (1988). Role of the arginine deiminase system in protecting oral bacteria and an enzymatic basis for acid tolerance. Appl Environ Microbiol 54, 1318-1324.

Chen, J. (2010). Listeria monocytogenes: molecular evolution and functional genomics under acidic conditions. $\mathrm{PhD}$ thesis, Zhejiang University, Hangzhou, China.

Chen, J., Zhang, X., Mei, L., Jiang, L. \& Fang, W. (2009a). Prevalence of Listeria in Chinese food products from 13 provinces between 2000 and 2007 and virulence characterization of Listeria monocytogenes isolates. Foodborne Pathog Dis 6, 7-14.

Chen, J., Luo, X., Jiang, L., Jin, P., Wei, W., Liu, D. \& Fang, W. (2009b). Molecular characteristics and virulence potential of Listeria monocytogenes isolates from Chinese food systems. Food Microbiol 26, 103111.

Chen, J., Jiang, L., Chen, X., Luo, X., Chen, Y., Yu, Y., Tian, G., Liu, D. \& Fang, W. (2009c). Listeria monocytogenes serovar $4 \mathrm{a}$ is a possible 
evolutionary intermediate between $L$. monocytogenes serovars $1 / 2 \mathrm{a}$ and $4 \mathrm{~b}$ and L. innocua. J Microbiol Biotechnol 19, 238-249.

Chen, J., Jiang, L., Chen, Q., Zhao, H., Luo, X., Chen, X. \& Fang, W. (2009d). $1 m o 0038$ is involved in acid and heat stress responses and specific for Listeria monocytogenes lineages I and II, and Listeria ivanovii. Foodborne Pathog Dis 6, 365-376.

Chen, J., Chen, Q., Jiang, J., Hu, H., Ye, J. \& Fang, W. (2010a). Serovar $4 \mathrm{~b}$ complex predominates among Listeria monocytogenes isolates from imported aquatic products in China. Foodborne Pathog Dis 7, 31-41.

Chen, J., Chen, Q., Jiang, L., Cheng, C., Bai, F., Wang, J., Mo, F. \& Fang, W. (2010b). Internalin profiling and multilocus sequence typing suggest four Listeria innocua subgroups with different evolutionary distances from Listeria monocytogenes. BMC Microbiol 10, 97.

Conte, M. P., Petrone, G., Di Biase, A. M., Ammendolia, M. G., Superti, F. \& Seganti, L. (2000). Acid tolerance in Listeria monocytogenes influences invasiveness of enterocyte-like cells and macrophage-like cells. Microb Pathog 29, 137-144.

Cotter, P. D. \& Hill, C. (2003). Surviving the acid test: responses of Gram-positive bacteria to low pH. Microbiol Mol Biol Rev 67, 429453.

Cotter, P. D., Gahan, C. G. \& Hill, C. (2000). Analysis of the role of the Listeria monocytogenes $\mathrm{F}_{0} \mathrm{~F}_{1}$-ATPase operon in the acid tolerance response. Int J Food Microbiol 60, 137-146.

Cotter, P. D., Gahan, C. G. \& Hill, C. (2001). A glutamate decarboxylase system protects Listeria monocytogenes in gastric fluid. Mol Microbiol 40, 465-475.

Cunin, R., Glansdorff, N., Piérard, A. \& Stalon, V. (1986). Biosynthesis and metabolism of arginine in bacteria. Microbiol Rev 50, 314-352.

de Chastellier, C. \& Berche, P. (1994). Fate of Listeria monocytogenes in murine macrophages: evidence for simultaneous killing and survival of intracellular bacteria. Infect Immun 62, 543-553.

De la Fuente, J. L., Martin, J. F. \& Liras, P. (1996). New type of hexameric ornithine carbamoyltransferase with arginase activity in the cephamycin producers Streptomyces clavuligerus and Nocardia lactamdurans. Biochem J 320, 173-179.

Degnan, B. A., Fontaine, M. C., Doebereiner, A. H., Lee, J. J., Mastroeni, P., Dougan, G., Goodacre, J. A. \& Kehoe, M. A. (2000). Characterization of an isogenic mutant of Streptococcus pyogenes Manfredo lacking the ability to make streptococcal acid glycoprotein. Infect Immun 68, 2441-2448.

Freitag, N. E., Port, G. C. \& Miner, M. D. (2009). Listeria monocytogenes - from saprophyte to intracellular pathogen. Nat Rev Microbiol 7, 623-628.

Fulde, M., Willenborg, J., de Greeff, A., Benga, L., Smith, H. E., Valentin-Weigand, P. \& Goethe, R. (2011). ArgR is an essential local transcriptional regulator of the $\operatorname{arc} A B C$ operon in Streptococcus suis and is crucial for biological fitness in an acidic environment. Microbiology 157, 572-582.

Glaser, P., Frangeul, L., Buchrieser, C., Rusniok, C., Amend, A., Baquero, F., Berche, P., Bloecker, H., Brandt, P. \& other authors (2001). Comparative genomics of Listeria species. Science 294, 849-852.

Griswold, A. R., Chen, Y. Y. M. \& Burne, R. A. (2004). Analysis of an agmatine deiminase gene cluster in Streptococcus mutans UA159. J Bacteriol 186, 1902-1904.

Gruening, P., Fulde, M., Valentin-Weigand, P. \& Goethe, R. (2006). Structure, regulation, and putative function of the arginine deiminase system of Streptococcus suis. J Bacteriol 188, 361-369.

Jiang, J., Chen, J., Cheng, C., Hu, H., Bai, F., Chen, N., Yan, G. \& Fang, W. (2011). Disruption of InlC2 enhances the internalization of Listeria monocytogenes by epithelial cells. World J Microbiol Biotechnol 27, 21552161.
Joseph, B., Przybilla, K., Stühler, C., Schauer, K., Slaghuis, J., Fuchs, T. M. \& Goebel, W. (2006). Identification of Listeria monocytogenes genes contributing to intracellular replication by expression profiling and mutant screening. J Bacteriol 188, 556-568.

Landete, J. M., Arena, M. E., Pardo, I., Manca de Nadra, M. C. \& Ferrer, S. (2008). Comparative survey of putrescine production from agmatine deamination in different bacteria. Food Microbiol 25, 882887.

Legrain, C. \& Stalon, V. (1976). Ornithine carbamoyltransferase from Escherichia coli W. Purification, structure and steady-state kinetic analysis. Eur J Biochem 63, 289-301.

Legrain, C., Stalon, V., Noullez, J. P., Mercenier, A., Simon, J. P., Broman, K. \& Wiame, J. M. (1977). Structure and function of ornithine carbamoyltransferases. Eur J Biochem 80, 401-409.

Liu, D. (2006). Identification, subtyping and virulence determination of Listeria monocytogenes, an important foodborne pathogen. J Med Microbiol 55, 645-659.

Llácer, J. L., Polo, L. M., Tavárez, S., Alarcón, B., Hilario, R. \& Rubio, V. (2007). The gene cluster for agmatine catabolism of Enterococcus faecalis: study of recombinant putrescine transcarbamylase and agmatine deiminase and a snapshot of agmatine deiminase catalyzing its reaction. J Bacteriol 189, 1254-1265.

Lucas, P. M., Blancato, V. S., Claisse, O., Magni, C., Lolkema, J. S. \& Lonvaud-Funel, A. (2007). Agmatine deiminase pathway genes in Lactobacillus brevis are linked to the tyrosine decarboxylation operon in a putative acid resistance locus. Microbiology 153, 2221-2230.

Marquis, R. E., Bender, G. R., Murray, D. R. \& Wong, A. (1987). Arginine deiminase system and bacterial adaptation to acid environments. Appl Environ Microbiol 53, 198-200.

Marron, L., Emerson, N., Gahan, C. G. \& Hill, C. (1997). A mutant of Listeria monocytogenes LO28 unable to induce an acid tolerance response displays diminished virulence in a murine model. Appl Environ Microbiol 63, 4945-4947.

Milillo, S. R., Badamo, J. M. \& Wiedmann, M. (2009). Contributions to selected phenotypic characteristics of large species- and lineage-specific genomic regions in Listeria monocytogenes. Food Microbiol 26, 212-223.

Naumoff, D. G., Xu, Y., Glansdorff, N. \& Labedan, B. (2004). Retrieving sequences of enzymes experimentally characterized but erroneously annotated: the case of the putrescine carbamoyltransferase. BMC Genomics 5, 52.

O'Driscoll, B., Gahan, C. G. \& Hill, C. (1996). Adaptive acid tolerance response in Listeria monocytogenes: isolation of an acid-tolerant mutant which demonstrates increased virulence. Appl Environ Microbiol 62, 1693-1698.

Orsi, R. H., den Bakker, H. C. \& Wiedmann, M. (2011). Listeria monocytogenes lineages: genomics, evolution, ecology, and phenotypic characteristics. Int J Med Microbiol 301, 79-96.

Ramón-Maiques, S., Marina, A., Guinot, A., Gil-Ortiz, F., Uriarte, M., Fita, I. \& Rubio, V. (2010). Substrate binding and catalysis in carbamate kinase ascertained by crystallographic and site-directed mutagenesis studies: movements and significance of a unique globular subdomain of this key enzyme for fermentative ATP production in bacteria. J Mol Biol 397, 1261-1275.

Ren, Y., Zhang, Y., Shao, S., Cai, Z., Feng, L., Pan, H. \& Wang, Z. (2007). Simultaneous determination of multi-component mycotoxin contaminants in foods and feeds by ultra-performance liquid chromatography tandem mass spectrometry. J Chromatogr A 1143, 48-64.

Ryan, S., Begley, M., Gahan, C. G. M. \& Hill, C. (2009). Molecular characterization of the arginine deiminase system in Listeria monocytogenes: regulation and role in acid tolerance. Environ Microbiol 11, 432-445. 
Sainz, G., Tricot, C., Foray, M. F., Marion, D., Dideberg, O. \& Stalon, V. (1998). Kinetic studies of allosteric catabolic ornithine carbamoyltransferase from Pseudomonas aeruginosa. Eur $J$ Biochem 251, 528-533.

Sleator, R. D., Watson, D., Hill, C. \& Gahan, C. G. (2009). The interaction between Listeria monocytogenes and the host gastrointestinal tract. Microbiology 155, 2463-2475.

Swaminathan, B. \& Gerner-Smidt, P. (2007). The epidemiology of human listeriosis. Microbes Infect 9, 1236-1243.

Vrancken, G., Rimaux, T., Wouters, D., Leroy, F. \& De Vuyst, L. (2009a). The arginine deiminase pathway of Lactobacillus fermentum IMDO 130101 responds to growth under stress conditions of both temperature and salt. Food Microbiol 26, 720-727.

Vrancken, G., Rimaux, T., Weckx, S., De Vuyst, L. \& Leroy, F. (2009b). Environmental $\mathrm{pH}$ determines citrulline and ornithine release through the arginine deiminase pathway in Lactobacillus fermentum IMDO 130101. Int J Food Microbiol 135, 216-222.

Ward, T. J., Ducey, T. F., Usgaard, T., Dunn, K. A. \& Bielawski, J. P. (2008). Multilocus genotyping assays for single nucleotide polymorphism-based subtyping of Listeria monocytogenes isolates. Appl Environ Microbiol 74, 7629-7642.

Wargnies, B., Lauwers, N. \& Stalon, V. (1979). Structure and properties of the putrescine carbamoyltransferase of Streptococcus faecalis. Eur J Biochem 101, 143-152.

Wu, B., Xia, C., Du, X., Cao, X. \& Shen, J. (2006). Influence of anti-FloR antibody on florfenicol accumulation in florfenicol-resistant Escherichia coli and enzyme-linked immunosorbent assay for detection of florfenicol-resistant E. coli isolates. J Clin Microbiol 44, 378-382.

Edited by: H. Ingmer 